\title{
The Influence of Copper Sulphate and Manganese Sulphate upon the Growth of Barley.
}

BY

\author{
W. E. BRENCHLEY, B.Sc., F.L.S., \\ Rothamsted Experimental Station.
}

With Plate XLVII, and four Figures in the Text.

$\mathrm{D}$ URING recent years a great deal of attention has been directed to the physiological action of certain chemical substances upon the growth of plants, particularly with regard to plant poisons. A theory has been put forward that all chemical substances which are deleterious to plant growth act universally as stimulative agents if they are only available in exceedingly minute quantities. An examination of the literature on the subject indicates that many of the experimental results are self-contradictory and that, as a general rule, little can be regarded as definitely settled.

In 1907 investigations were begun at the Rothamsted Laboratory to determine, if possible, the limits of concentration of a few specified salts necessary to produce either a toxic or stimulative effect upon the growth of certain of the higher plants. The experiments were carried on by means of water-cultures, as they afford the most ready method of controlling the nutrient and toxic substances supplied to the plants. Great care was observed to eliminate, as far as was practicable, any disturbance of the experimental results by outside causes, such as dirty bottles, corks, \&c. The plants were grown singly in clear glass bottles fitted with bored corks to support the plants. These corks were either new or else were sterilized $\mathrm{n}$ an autoclave previous to use in order to kill off any adherent mould spores or green algal cells. The bottles were filled with culture solution to within an inch from the top, and the plants after germination in fresh damp sawdust were lightly held in position in the cork by means of non-absorbent cotton wool. Great care was taken to keep the latter dry, as damp wool, especially in the early stages of growth, would prove a fruitful source of loss of plants on account of disease and bacterial action. The bottles were then covered with closely fitting brown paper coats to exclude light from the solutions and roots.

[Annals of Botany, Vol. XXIV. No. XCV. Ju1y, 1910.] 
The Laboratory distilled water used for ordinary chemical purposes exerts a deleterious action on the growth of plants, especially upon the roots, probably on account of the fact that it is delivered through copper pipes (Pl. XLVII, Fig. I). All such water was rejected for experimental purposes, and that used in the preliminary investigations was specially made with a glass still.

\section{Copper Sulphate. $\mathrm{CuSO}_{4} \cdot{ }_{5} \mathrm{H}_{2} \mathrm{O}$.}

Experiments were made to ascertain the effect of varying concentrations of Copper as Sulphate on the growth of Barley :-

(a) in the absence of any nutrient salts;

(b) in the presence of a full complement of nutrient salts.

(a) No mutrients.

Duplicate series of plants were grown with seven dilutions of copper sulphate ${ }^{1}$ in distilled water, varying from I : I 2,500 to I : I,000,000 C.S., ${ }^{2}$ two duplicate checks being also made, one in pure glass distilled water, one in laboratory distilled water (called for convenience $\mathrm{Cu}$ distilled water). In these very early experiments, dealing with small numbers of plants, the individuals were periodically measured, root and shoot. Later on this was abandoned, as the results did not repay the time and labour expended; the method of comparison of dry weights was adopted in its stead and proved far more satisfactory.

In the series under consideration the plants were allowed to grow for a month, and it was found that the root and shoot behaved somewhat differently with regard to similar concentrations of C.S. Root development was entirely checked by every concentration of C.S. from I : I2,500 to I : I,000,000. A little growth had taken place in the $\mathrm{Cu}$ distilled water, but this did not in any way approach that in glass distilled water. The shoot, on the other hand, showed approximately a gradual increase in growth with decreasing strength of C.S., the best growth occurring in the glass distilled water. These results seem to indicate that the barley root is very sensitive to minute traces of copper sulphate, even one part in $1,000,000$ being sufficient to check growth. It is evident, though, that even the strongest concentration, I : I 2,500, does not actually kill the plant, at any rate at once, since the shoot continues its growth to a certain extent, living on the reserve materials in the grain. Similar results were obtained from a second set of plants grown later on in the year.

(b) With nutrients.

Duplicate series of plants were grown with similar concentrations of C.S. as under $(a)$, but containing a definite quantity of nutrient salts in addition.

${ }_{1}^{1}$ For convenience $\mathrm{CuSo}_{4} \cdot 5 \mathrm{H}_{2} \mathrm{O}$ is expressed throughout as C.S.

2 All concentrations are expressed in grams of $\mathrm{CuSo}_{4} \cdot 5 \mathrm{H}_{2} \mathrm{O}$ to cubic centimetres water. Thus I: I 2,500 C.S. means I gram $\mathrm{CuSo}_{4} \cdot 5 \mathrm{H}_{2} \mathrm{O}$ crystals to $\mathrm{I} 2,500$ c.c. $\mathrm{H}_{2} \mathrm{O}$. 
Each litre of culture solution ${ }^{1}$ contained, besides the requisite amount of copper sulphate:

Potassium Nitrate . . . I gram.

Magnesium Sulphate . . . 0.5,

Calcium Sulphate . . . . 0.5 ,
Sodium Chloride . . . 0.5 gram.

Potassium Phosphate . . 0.5 ,

Ferric Chloride . . Trace (0.04 gram).

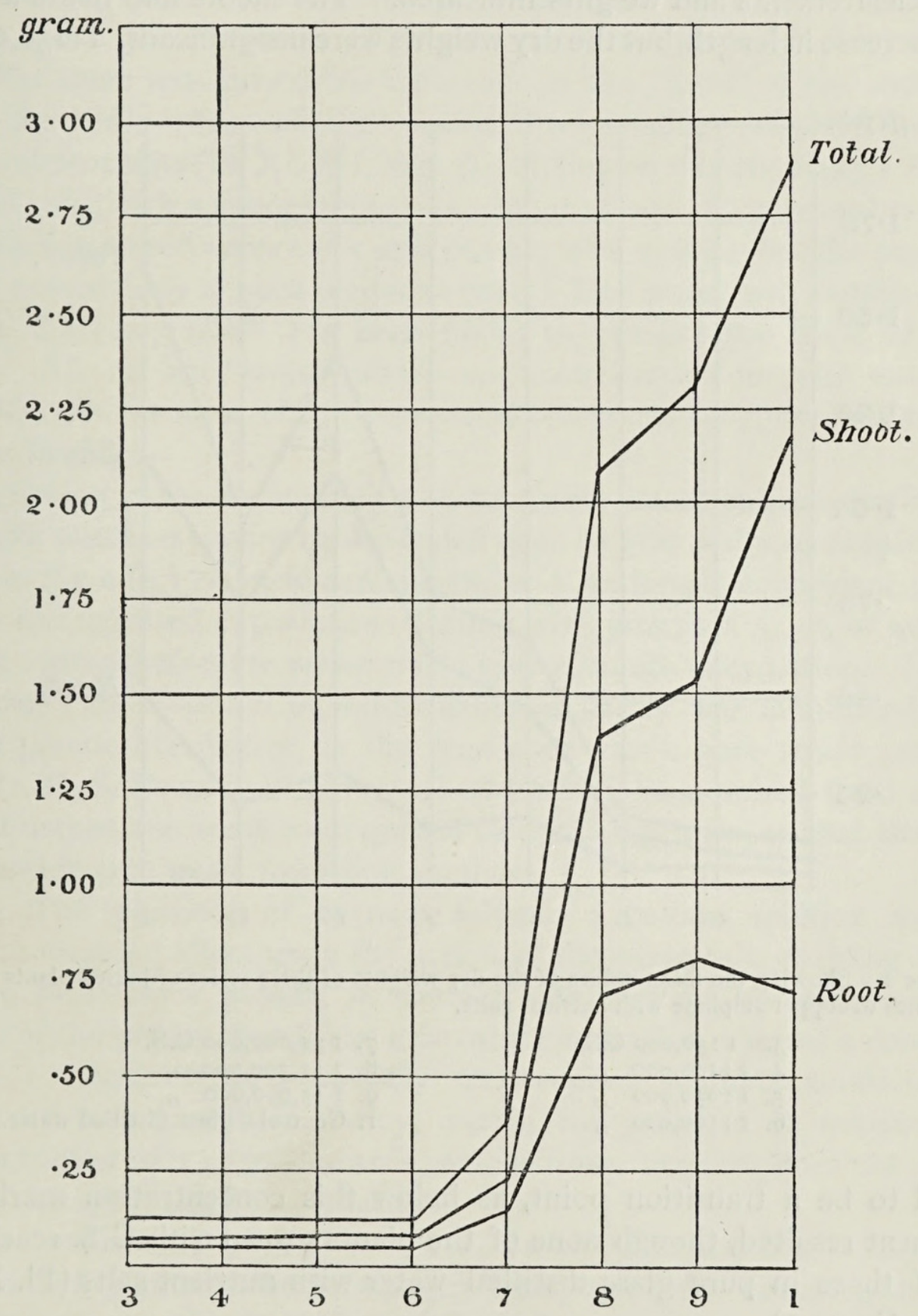

Curve I. Showing the result of the initial experiment on the action of copper sulphate on the growth of barley in the presence of nutrient salts.
3. I : I 2,500 C.S
4. I : 25,000 ,
5. I : 50,000,
6. I : 100,000 ,

7. $\quad I: 250,000$ C.S.

8. I : 500,000 ,

9. I : I, 000,000 ,

I. Control-glass distilled water.

1 D. H. Scott, Structural Botany (Flowering Plants.), p. 202. 
These plants were measured during growth for about seven weeks, and at the close of the experiment those in one series were divided into root and shoot, separately dried for two or three days in a steam oven at $100^{\circ} \mathrm{C}$., and weighed, in order to find the amount of dry matter present.

I : I 2,500 to I : I00,000 C.S. solution checked the root growth entirely, as both measurements and weights indicated. The shoots had made a certain slight increase in length, but the dry weights were insignificant. I:250,000 C.S.

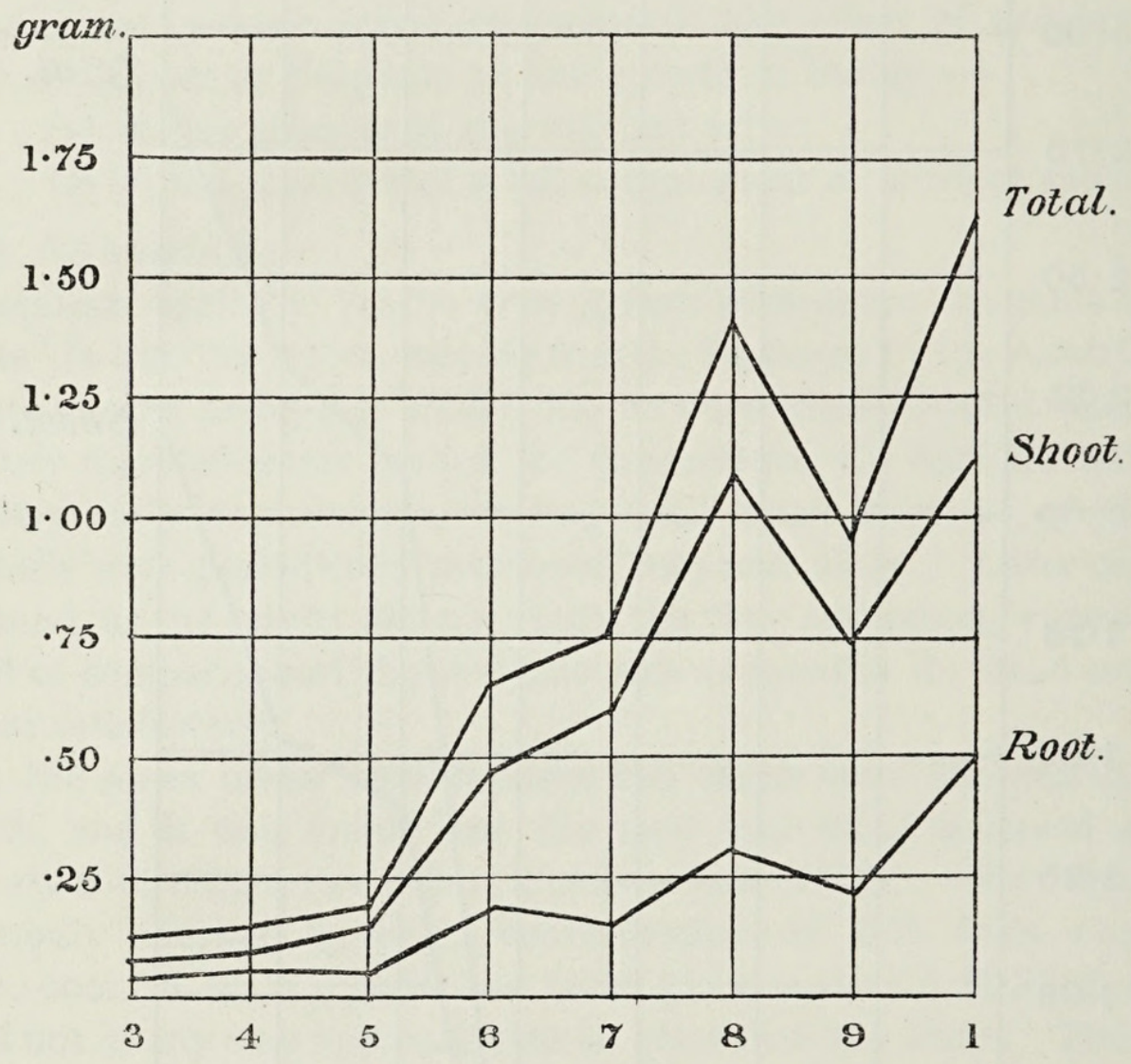

Curve 2. Showing the mean values of the dry weights of three series of barley plants grown in the presence of copper sulphate with nutrient salts.
3. I : 50,000 C.S.
4. I : 100,000,
5. I : 250,000,
6. I : 500,000,
7. I : I,000,000 C.S.
8. I : $2,500,000$,
9. I : $5,000,000$,"
I. Control-glass" distilled water.

seemed to be a transition point, as below this concentration marked improvement resulted, though none of the plants grown with C.S. reached the level of those in pure glass distilled water with nutrient salts (Pl. XLVII, Fig. 2: Curve I).

Further experiments made later in the year afforded similar results. In this case the concentration of the toxic salt was further reduced to I : $5,000,000$, but even at this dilution the C.S. seemed to exercise a deleterious action, as the plants did not make as much growth as in its absence. (Curve 2.) 
Since it was anticipated that the manufacture of sufficient glass distilled water would prove a difficulty when the investigations were extended, tests were made to find a satisfactory substitute. Pure glass distilled water was shaken up with pieces of metallic silver and aluminium respectively, and allowed to stand on the metals for at least an hour. Food solutions were then made up with the water so prepared, and test plants were grown in them, with parallel controls in pure-water culture solutions. It was found that there was little or no difference in the growth of the two sets of plants, the toxic effect of the metals, if any, being completely masked by the nutrient salts (Pl. XLVII, Fig. 3). Acting on this discovery a Brown's 'chemist' still with a condensing arrangement of pure silver was obtained, in which the condensed water came into contact with nothing but the pure silver until it passed into a glass delivery tube. The water was finally filtered through charcoal, which has been found to remove the toxic effects of metals. All the later water-culture work was carried out with water thus prepared. At the close of the experimental work in 1907 , two points stood out very clearly:-

(I) Owing to the individuality of the plants, investigations dealing only with small numbers cannot be depended upon to give really reliable information as to the effect of various strengths of a toxic salt upon plant growth. To this end repeated experiments dealing with groups of 5 , 10, or 20 plants for each concentration are necessary to give accurate information. In these experiments the question of individuality in barley was eliminated to the greatest practicable degree, as the seed used was a pure strain (obtained from Mr. E. S. Beaven, Warminster) which had been raised from a single seed. Further, the seeds were graded before being sown, so that they only varied within 0.02 gram from one another.

(2) The presence of nutrient salts in a culture solution exercises a definite masking effect upon the action of the toxic salt, enabling a plant to make satisfactory growth in contact with a much more concentrated solution of the poison than it can otherwise endure, i. e. whereas a concentration of $\mathrm{I}: \mathrm{I}, 000,000$ (and possibly less) copper sulphate solution alone entirely inhibits growth in barley, yet in the presence of nutrient salts a concentration of $I: 250,000$, at least four times as great, does not prevent growth, though it decidedly checks it.

The preliminary year's work had shown that the best results were obtained with plants grown between February and July, as during the early winter months practically no growth is made, and seedlings raised after the early part of June are very apt to fail.

Early in 1908 extended experiments were started with twenty parallel series, each consisting of eight concentrations of C.S. ranging from $I: 50,000$ to I : $10,000,000$, with a control in distilled water, nutrient salts being added in each case. The seeds were graded between 0.04 and 0.06 grams and the 


\section{6

plants were allowed to grow on for seven or eight weeks. The series was very good, but even here the plants showed great individuality, as is seen in Table I, the variation from the mean being as much as $30 \%$ to $40 \%$ in some cases. The curve of the means (Curve 3 ) shows that I : 50,000 C.S. to I : 250,000 C.S. practically checked growth in nearly every case, I : 500,000 C.S. marking the critical point after which growth progressed rapidly. A possible stimulus is indicated with $\mathrm{I}: 5,000,000$ C.S., but with such large variations it was recognized that this might easily be due to experimental error. To

\begin{tabular}{|c|c|c|c|c|c|c|c|c|c|}
\hline & 2. & 3 . & 4. & 5. & 6. & 7. & 8. & 9. & I. \\
\hline & Gram. & Gram. & Gram. & Gram. & Gram. & Gram. & Gram. & Gram. & Gram. \\
\hline $\begin{array}{l}\mathrm{A} \\
\mathrm{B}\end{array}$ & $\begin{array}{l}\text {. } 123 \\
\text {.100 }\end{array}$ & $\begin{array}{l}\text {. I32 } \\
\text {. IO5 }\end{array}$ & $\begin{array}{l}.135 \\
.076\end{array}$ & $\begin{array}{l}\cdot \text { I } 75 \\
\cdot \text { IO7 }\end{array}$ & $\begin{array}{l}\cdot 416 \\
\cdot 389\end{array}$ & $\begin{array}{l}.965 \\
.758\end{array}$ & $\begin{array}{r}.476 \\
\text { r.01 } 8\end{array}$ & $\begin{array}{l}.747 \\
.787\end{array}$ & $\begin{array}{l}\cdot 324 \\
.987\end{array}$ \\
\hline C & $\cdot 106$ & .092 & $\cdot \mathrm{IO}_{2}$ & .I 37 & .566 & $.73^{2}$ & .800 & 761 & .818 \\
\hline D & $\cdot 132$ & .083 & $\cdot{ }^{\prime} 5^{\circ}$ & - 109 & $.64 \mathrm{I}$ & $.90 \mathrm{I}$ & $\cdot 795$ & $\cdot 93^{2}$ & $\cdot 77 \mathrm{I}$ \\
\hline $\mathrm{E}$ & .097 & .098 & - II 2 & $\cdot 196$ & .659 & .736 & .767 & $\cdot 759$ & $.95^{8}$ \\
\hline $\mathrm{F}$ & .102 & - & . 106 & -II 3 & .283 & .529 & .662 & $\cdot 718$ & .884 \\
\hline $\mathrm{G}$ & - IIO & - & .099 & .290 & .239 & $\cdot 9^{2} \mathrm{I}$ & .632 & 1.030 & .984 \\
\hline $\mathrm{H}$ & .083 & - & .096 & .304 & $\cdot 447$ & · 18 & .718 & $.83^{2}$ & .869 \\
\hline I & - I I I & - & - 145 & .162 & $\cdot 344$ & .762 & 960 & $\cdot 793$ & .501 \\
\hline $\mathrm{K}$ & .088 & - & .099 & .210 & $\cdot 337$ & $\cdot 318$ & .698 & .672 & $\cdot 95^{8}$ \\
\hline $\mathrm{L}$ & .073 & $\cdot 102$ & .107 & $\cdot 183$ & .408 & .886 & I. 236 & .442 & .283 \\
\hline M & .089 & $\cdot \mathrm{II}_{4}$ & $.080^{\circ}$ & - I 57 & $\cdot 33 \mathrm{I}$ & .901 & .984 & .839 & $.93^{6}$ \\
\hline $\mathrm{N}$ & .105 & - I I I & $\cdot{ }^{1} 47$ & $\cdot 355$ & $\cdot 375$ & $\mathrm{I} \cdot \mathrm{IO} 4$ & I.088 & .928 & 1.029 \\
\hline $\mathrm{O}$ & . 118 & - III I & - 145 & - I 7 & $.47^{2}$ & .734 & .980 & .833 & 1.074 \\
\hline $\mathrm{P}$ & . II 6 & .082 & - II 2 & - 189 & .323 & .183 & .883 & .868 & .916 \\
\hline Q & . 05 & - 129 & $\cdot 13 \mathrm{I}$ & $\cdot 146$ & .716 & $I \cdot 182$ & $\mathrm{I} \cdot 26 \mathrm{I}$ & $\cdot 932$ & 1.033 \\
\hline $\mathrm{K}$ & .104 & .079 & - I I 6 & $\cdot{ }^{-1} 5^{2}$ & . I 26 & 1.039 & $.95^{\mathrm{I}}$ & .844 & I. I 20 \\
\hline $\mathrm{S}$ & .085 & .IOI & - II 4 & .295 & $\cdot{ }^{-1} 64$ & - I93 & .899 & .837 & I.II 4 \\
\hline $\mathrm{T}$ & -179 & . 120 & .168 & .268 & .547 & .907 & $\mathrm{I} .06 \mathrm{I}$ & $\cdot 976$ & I. 2 II \\
\hline U & .124 & $\cdot 123$ & .086 & .234 & $\cdot 3^{21}$ & .598 & .854 & I.025 & .670 \\
\hline Mean. & $\cdot 107$ & $\cdot 105$ & - II 6 & -I94 & $\cdot 405$ & $\cdot 753$ & $.88 \mathrm{I}$ & .827 & $.87^{2}$ \\
\hline
\end{tabular}

Table I. Actual dry weights of twenty series of barley plants, A-U, grown in varying strengths of copper sulphate with nutrient salts. The mean dry weight for each concentration of the toxic salt is also given.
2. I : 50,000 C.S.
3. I : 100,000 ,
4. I : $25^{\circ}, 000$,
5. I : 500,000 ,",
6. I : I,000,000",

7. I : 2,500,000 C.S.

8. I : $5,000,000 \quad$,

9. I : $10,000,000$,",

I. Control-distilled water.

determine the magnitude of the latter factor the usual method of least squares was followed, the individual results being first recalculated by taking the mean of the control series as 100 . In this way the following table was obtained:-

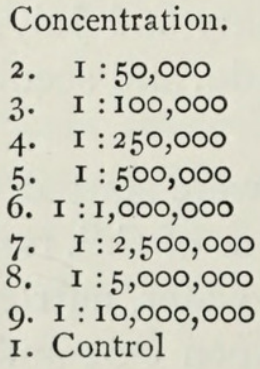

Concentration

3.

4. I : 250,000

5. I : 500,000

6. I : I, , ००, , ०

7. I : $2,500,000$

9. I : $10,000,000$

I. Control 
From this table and the resulting curve (Curve 3 ) it is evident that the possible stimulus with $I: 5,000,000$ C.S. does fall within the range of experimental error. This was confirmed by recalculating the means of

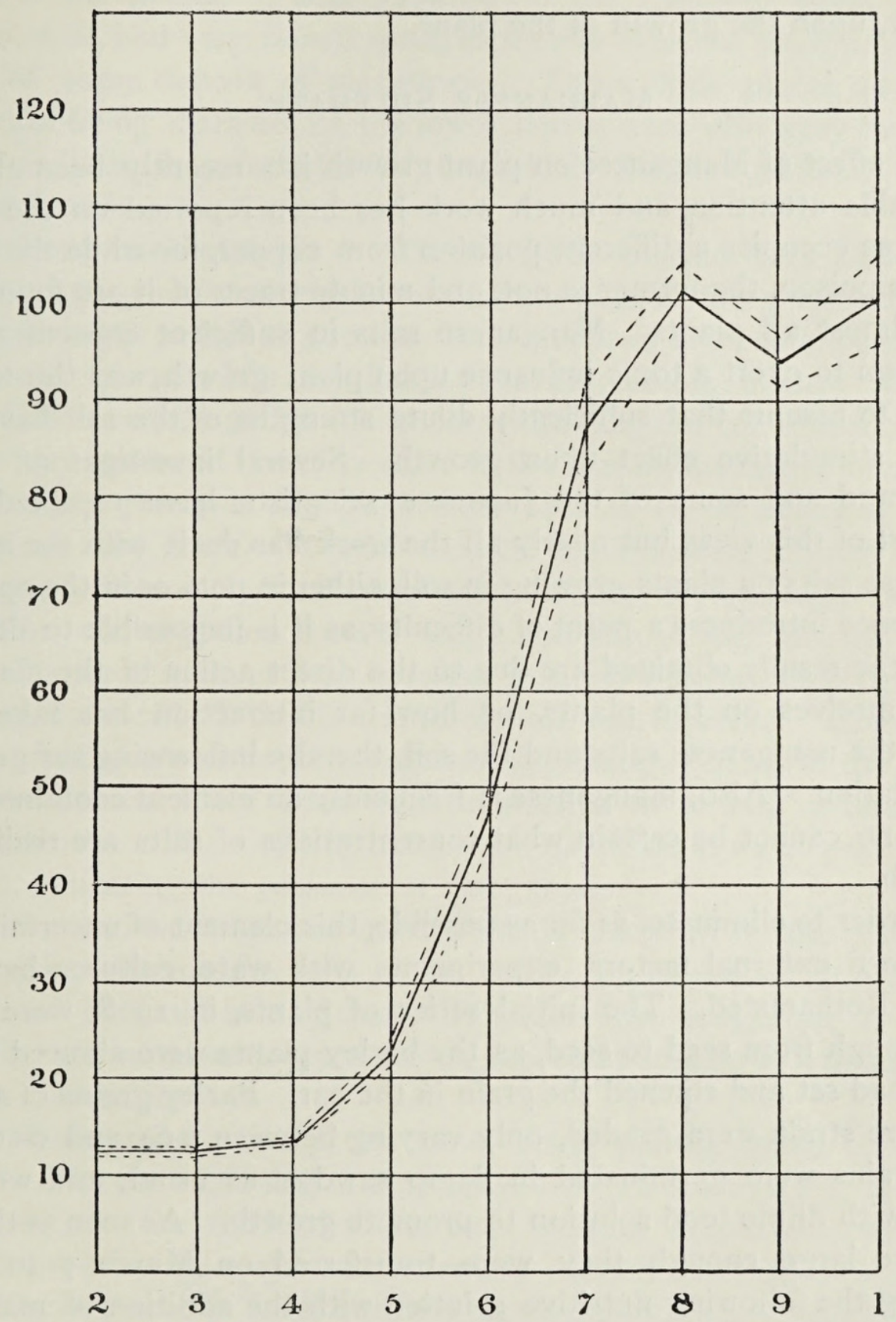

Curve 3. The black line shows the mean of the dry weights of twenty series of barley plants grown with copper sulphate and nutrient salts. The dotted lines indicate the limits of probable experimental error for each concentration of the toxic salt. (See Table I for concentrations.)

I : 5,000,000 C.S., I : $10,000,000$ C.S. and the control results after rejection of the individual results below 60 . This corrected mean fell within the range of experimental error in the first two cases, and above it in the control, and indicated that no stimulus occurred with $I: 5,000,000$ C.S. 


\section{Brenchley.-The Influence of Copper Sulphate and}

To sum up, it appears that copper, as sulphate, does not exert a stimulative action on barley, however small the concentration, but that the toxic effect of the salt gradually decreases with the concentration, until strengths of $I: 5,000,000$ and under have no appreciable effect, either toxic or stimulant, upon the growth of the plant.

\section{Manganese Sulphate.}

The effect of Manganese on plant growth has recently been attracting considerable attention, and much work has been reported on the subject. Manganese occupies a different position from copper, for while the latter is a definite poison, the former is not, and minute traces of it are found in the ash of almost all plants. Manganese salts in sufficient concentration are well known to exert a toxic influence upon plant growth, and the tendency has been to assume that sufficiently dilute strengths of the salt have a consistently stimulative effect upon growth. Several investigators, notably M. Bertrand and some of the Japanese scientists, have reported results in support of this view, but nearly all the work has dealt with the action of manganese salts on plants growing in soil, either in pots or in the open field. This at once introduces a point of difficulty, as it is impossible to determine how far the results obtained are due to the direct action of the manganese salts themselves on the plants, or how far interaction has taken place between the manganese salts and the soil, thereby influencing the growth of the vegetation. Also, manganese is frequently an element contained in the soil, so one cannot be certain what concentrations of salts are really being dealt with.

In order to eliminate, as far as possible, this element of uncertainty due to unknown external factors, experiments with water-cultures have been made at Rothamsted. The initial series of plants, in 1908 , were carried right through from seed to seed, as the barley plants were allowed to grow till they had set and ripened the grain in the ear. Barley grains of an absolutely pure strain were graded, only varying between 0.04 and 0.06 gram. These grains were germinated in damp sawdust as usual, and were then watered with dilute food solution to promote growth. As soon as the seedlings were large enough they were transferred on March 7 to bottles containing the following nutritive solution with the addition of manganese sulphate $\left(=\mathrm{MnSo}_{4} \cdot 5 \mathrm{H}_{2} \mathrm{O} .=\right.$ M.S. $)$ in concentrations varying from $\mathrm{I}: 10,000$ to $I: I, 000,000,000$, with a control containing no M.S.

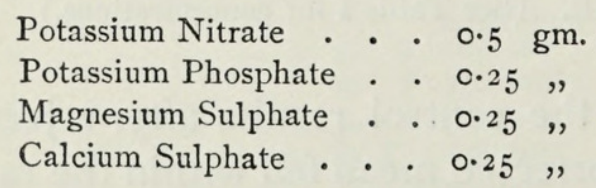

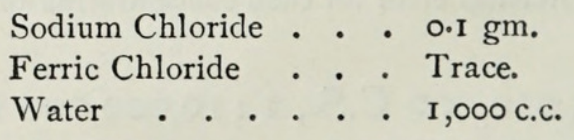

Five similar sets were grown to put a check on individuality. As ordinary ferric chloride usually contains a certain small percentage of 
manganese, Kahlbaum's sublimed ferric chloride was used to ensure its purity.

By April 8, about four weeks after the start, marked differences were manifest in the plants. Those growing in the strongest toxic solutions I : 10,000 M.S., had very brown roots, especially near the seed, probably on account of some deposit of manganese. These same plants gave every indication of being diseased, as the lower leaves were also very brown and appeared to be badly infected with rust, which died out gradually towards the upper leaves.

The next concentration I : 100,000 M.S. showed very little brown coloration on the roots and much less discoloration of the lower leaves. At a weaker strength still, I : I,000,000 M.S. and less, the roots were strong, healthy, and white, while the indications of possible disease were very slight and died out altogether lower down the range of concentration.

This appearance of 'rust' so early in the season was rather unexpected, so, as no other plants in the greenhouse seemed to be attacked, further investigations were made. A microscopical examination showed no signs of any fungal disease, but indicated that the cells were simply dead and brown while retaining their normal shape and size, at any rate in the early stages. The dead cells at first occurred in small patches which gradually spread and coalesced till finally the whole leaf was involved. Appearances pointed to death on account of manganese poisoning. Some of the affected leaves were detached and fused with a mixture of sodium carbonate and potassium nitrate. The resulting mass when dissolved in water gave a green coloration, indicating the presence of manganese.

It is thus evident that the manganese is taken up by the plant roots and finally deposited in the cells of the leaves, which are killed if the concentration of the salt is sufficient. Whether the manganese is further excreted by the leaves and deposited on the outer surface is a point that is not as yet cleared up.

The plants grew steadily, one series being photographed on May I, eight weeks from the beginning of the experiment (Pl. XLVII, Fig. 4). After eleven weeks, as the food solutions were getting exhausted and unable to support growth, the roots were carefully washed in distilled water, and the plants were placed in fresh nutritive solutions with a new quota of manganese sulphate, the concentrations remaining the same. At this date it was evident that manganese was deposited in the leaves even at so low a concentration as $I$ : $I, 000,000$ M.S. and in some cases traces could even be observed in $\mathrm{I}: \mathrm{I0}, 000,000$ M.S. By June 2, after three months' growth, most of the plants began to show ear, and by July I4, when the plants were harvested, a large proportion of the ovules had set and ripened to fully developed grains.

An examination of the plants at the time of harvesting indicated that 
the varying concentration of toxic salt had apparently not influenced the actual number of ears produced, but the grains had reached various stages of ripeness. The grains from the controls and from the manganese solutions of $I$ : I,000,000 and less were to be regarded as ripe, being hard and yellow. The ears resulting from a concentration of $\mathrm{I}: \mathrm{I00,000}$ M.S. yielded a mixed crop, some of the grains being ripe, some half ripe, and others green. With I : I0,oco M.S. practically all the grains were green. It is thus evident that the stronger concentrations of manganese sulphate have a definite retarding action on the ripening of the grain in the ear, and the indications are that as the strength of the toxic salt decreases this retarding influence gets less. Possibly the lowest strengths of the salt have no influence in this respect one way or the other.

On being finally removed from the culture solutions the roots of the plants were carefully washed in two or three changes of distilled water to remove adherent extraneous salts as completely as possible. The grain was shelled out from the ears, and the roots, shoots, and grain were dried separately for about three days at $100^{\circ} \mathrm{C}$., all the plants from a similar concentration of toxic salt being placed together. It is to be regretted that the individual plants were not kept apart and weighed separately, as has been done in the more recent experiments.

The dry weights obtained are shown in the following table :--

\begin{tabular}{|c|c|c|c|c|c|}
\hline & Shoot. & Root. & Shoot + Root. & Grain. & Shoot + Root + Grain. \\
\hline I. & $39 \cdot 140$ & $6 \cdot 282$ & $45 \cdot 422$ & $7 \cdot 464$ & $5^{2 \cdot 886}$ \\
\hline 2. & $26 \cdot 670$ & $4 \cdot 409$ & $3^{1} \cdot 079$ & $3 \cdot 85^{2}$ & $34 \cdot 93 \mathrm{I}$ \\
\hline 3 . & $37 \cdot 140$ & 5.020 & $42 \cdot 160$ & $5 \cdot 99^{6}$ & $48 \cdot 156$ \\
\hline 4 . & $40 \cdot 5^{6} 5$ & $5 \cdot 89 \circ$ & $4^{6 \cdot 455}$ & $1 \cdot 709$ & $48 \cdot 164$ \\
\hline 5. & $47 \cdot 900$ & $5 \cdot 780$ & $53 \cdot 680$ & $4 \cdot 635$ & $5^{8 \cdot 315}$ \\
\hline 6. & $45 \cdot 9^{2} 5$ & 6.630 & $5^{2 \cdot 555}$ & $6 \cdot 44^{\circ}$ & $5^{8 \cdot 995}$ \\
\hline
\end{tabular}

A consideration of the total dry weight, including the grain, indicates a very considerable depression in (2), which is obviously beyond the limits of experimental error. A possible slight depression seems to be shown in (3) and (4), and a stimulus in (5) and (6) as compared with the controls.

As the dry weight of the grain varies so much throughout the series, a truer estimate may perhaps be obtained by dealing only with the dry weights of the roots and shoots, which are fairly comparable.

A rather different estimate of the state of the case is obtained from these figures. The striking depression with I : I0,000 M.S. is still evident, and also a possible slight depression with (3) I : I00,000 M.S., but in (4) the apparent depression was due to the failure of the grain, as the new figures show that this concentration has little effect upon the growth, the balance possibly being in favour of a slight stimulus. The stimulative effect of (5) and $(6)$ is real. 
Manganese Sulphate upon the Growth of Barley. $\quad 58 \mathrm{I}$

Two points stand out clearly from this set of results :--

(I) The higher concentrations of manganese sulphate have a decided retarding effect upon the ripening of the grain.

(2) While strong solutions of manganese sulphate exert a toxic influence upon the growth of barley, very dilute solutions have a definite stimulative effect.

A later series of tests was carried out with pedigree ' Plumage' Barley, with the seeds graded to 0.05 and 0.07 gram, in which the plants were only

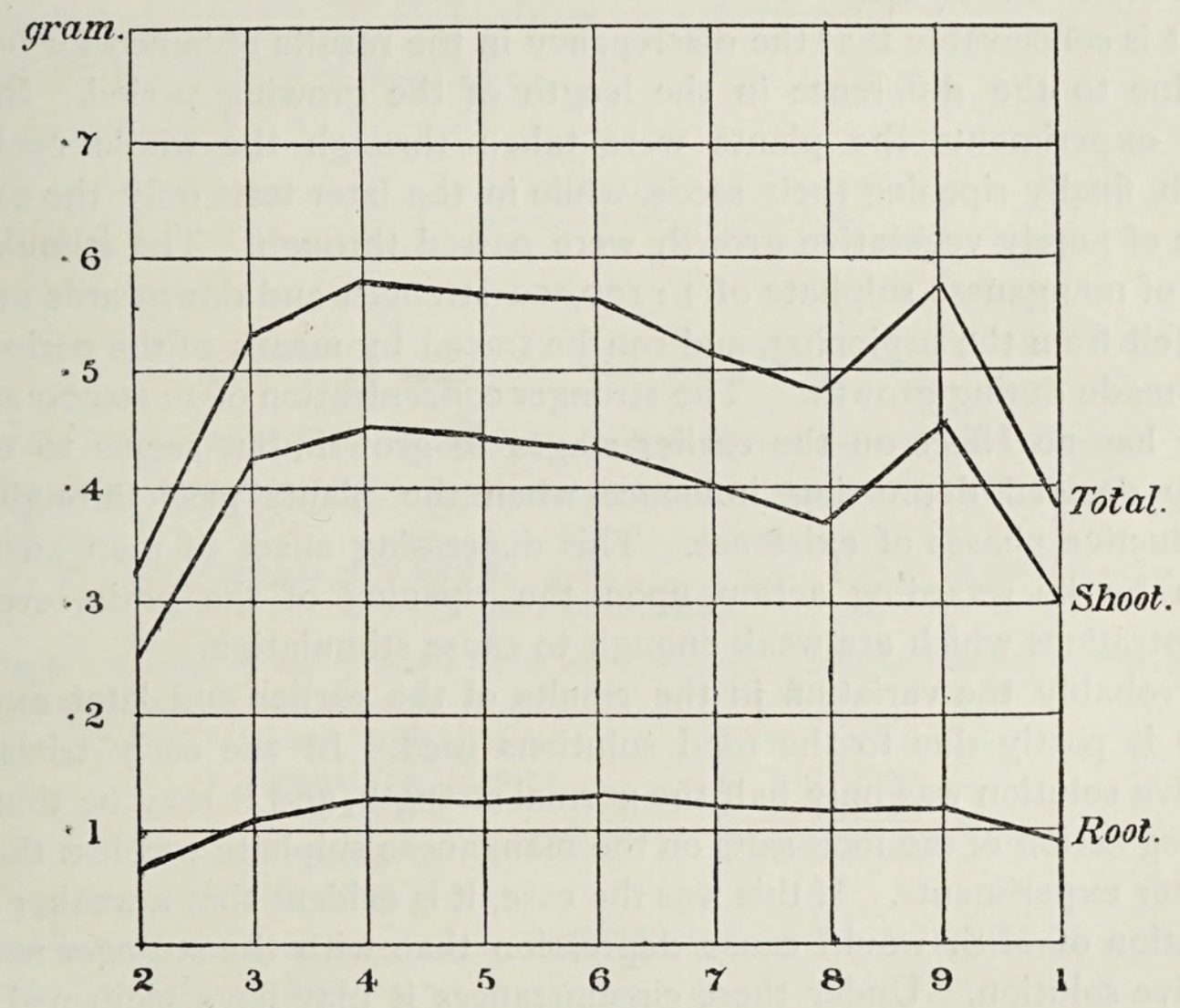

Curve 4. Showing the mean value of the dry weights of ten series of barley plants grown with manganese sulphate and nutrient salts.

$$
\begin{aligned}
& \text { 2. I : I0,000 M.S. } \\
& \text { 3. I : } 100,000,, \\
& \text { 4. I : } 1,000,000,, \\
& \text { 5. I : } 5,000,000, \\
& \text { 6. I : } 10,000,000,,
\end{aligned}
$$

7. I : $50,000,000$ M.S.

8. I : $100,000,000$, ,

9. I : $1,000,000,000$,,

I. Control-distilled water.

grown for a limited period, not being allowed to reach the flowering stage. In these tests the normal food solution was used (see copper sulphate experiments) at about double the concentration of the early manganese sets.

Five weeks from the start the 'browning' of the roots and discoloration of the lower leaves with I : I0,000 M.S. was manifest, and also at this date it was evident that all strengths of solution from I : 100,000 M.S. downwards were supporting plants which appeared better than the controls. This phenomenon was consistent through ten similar sets, and continued up to 
the time of harvesting, after about seven weeks' growth, as was borne out by means of the dry weights (Curve 4 ).

Although the plants with I : I0,000 M.S. had very brown roots and showed the characteristic deposit in the leaves, yet, so far as weight went, there was practically nothing to choose between them and the controls, in fact, in some cases, the plants grown with the strong concentration of manganese were rather better than those without it.

Parallel results were obtained from a similar series of ten sets of plants grown later in the year.

It is conceivable that the discrepancy in the results obtained for barley was due to the difference in the length of the growing period. In the initial experiments the plants were taken through the whole cycle of growth, finally ripening their seeds, while in the later tests only the earlier stages of purely vegetative growth were passed through. The stimulative effect of manganese sulphate of I : I00,000 strength and downwards makes itself felt from the beginning, and can be traced by means of the periodical notes made during growth. The stronger concentration of I : I0,000 apparently has no effect on the earlier stages of growth, but seems to exert a very decided depressing influence when the plants pass through the reproductive phases of existence. This depressing effect of manganese is shown by its retarding action upon the ripening of the grain, even in concentrations which are weak enough to cause stimulation.

Probably the variation in the results of the earlier and later experiments is partly due to the food solutions used. In the early trials the nutritive solution was only half the normal strength, and it may be that the masking action of the food salts on the manganese sulphate was less than in the later experiments. If this was the case, it is evident that a weaker concentration of M.S. would cause depression than with the stronger normal nutritive solution. Under these circumstances it may have happened that while I : I0,000 M.S. exercised a depressing influence with the weaker food solution, the same effect with the normal amount of salts would only have been obtained with a concentration of manganese sulphate outside the range of the experiments under consideration.

\section{Summary.}

I. The action of plant poisons in dilute solutions is masked by the presence of nutrient salts, which thus enable plants when grown in such solutions as water-cultures to endure a much greater concentration of the toxic substance than in the absence of nutrients.

2. Copper sulphate, which is a definite poison to Barley, does not have any stimulative effect in very dilute solutions, even at so low a concentration as I : $10,000,000$ C.S. 
Manganese Sulphate upon the Growth of Barley. $\quad 583$

3. Manganese sulphate, though not an actual toxic to Barley, retards the growth very considerably if supplied in moderate quantities. Minute traces of the salt have a decided stimulative action both on the root and shoot.

4. When supplied in sufficient concentration manganese is taken up by the plant and deposited in the lower leaves.

In conclusion, I have to express my indebtedness to Mr. A. D. Hall for the valuable advice he has given me during the progress of the experiments, and also to Dr. N. H. J. Miller for assisting me by taking the photographs reproduced in this paper.

\section{EXPLANATION OF PLATE XLVII.}

Illustrating Miss Brenchley's Paper on the Influence of Poisons on Barley.

Fig. I. Photograph showing the deleterious effect of copper distilled water on the growth of plants (Peas).

I, 3. Peas growing in glass distilled water. 2, 4. Peas in $\mathrm{Cu}$ distilled water.

(No nutrient salts.)

Fig. 2. A series of barley plants about six weeks old grown in different concentrations of copper sulphate in the presence of nutrient salts.
I. Glass distilled water.
6. I : 100,000 C.S.
2. Copper distilled water.
7. I : 250,000 ,
3. I : I 2,500 C.S.
8. I : 500,000 ,
4. I : 25,000,
9. I : I,०00,000, ,
5. I : 50,000 ,

Fig. 3. Photograph showing the effect of distilled water, differently prepared, upon the growth of plants-Peas. (No nutrients.)

I. Glass distilled water.

3. Glass distilled water which had been allowed

2. $\mathrm{Cu}$ distilled water. to stand in contact with pure silver for one hour.

Fig. 4. A series of barley plants grown with varying concentrations of manganese sulphate, in the presence of nutrient salts.
I. Control-distilled water.
2. I : 10,000 M.S.
4. I : I,000,000 M.S.
3. I : 100,000 ,
5. I : $10,000,000$,
6. I : $100,000,000$,, 
Annals of Botany',
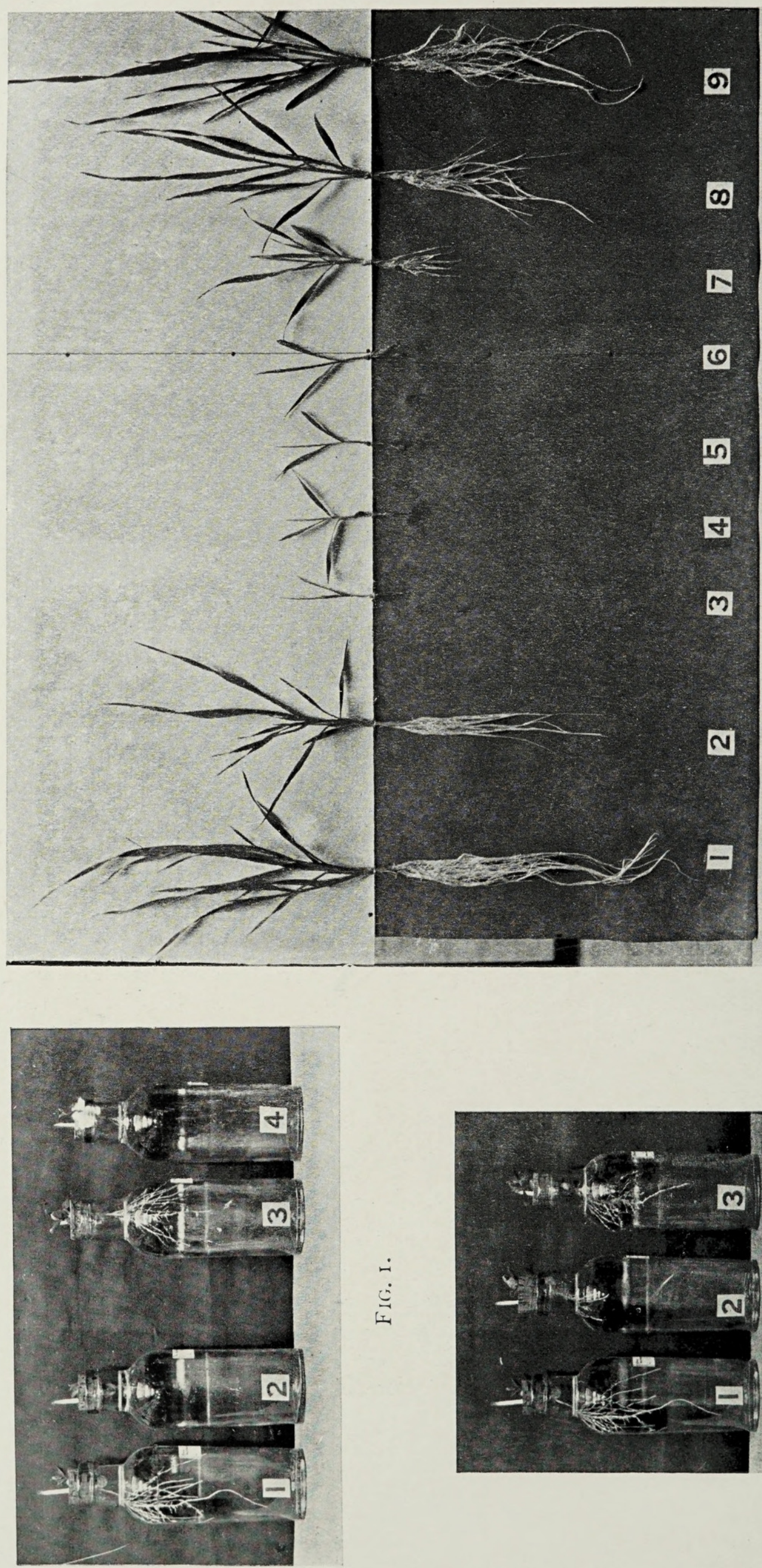

$\stackrel{i}{\dot{b}}$ 


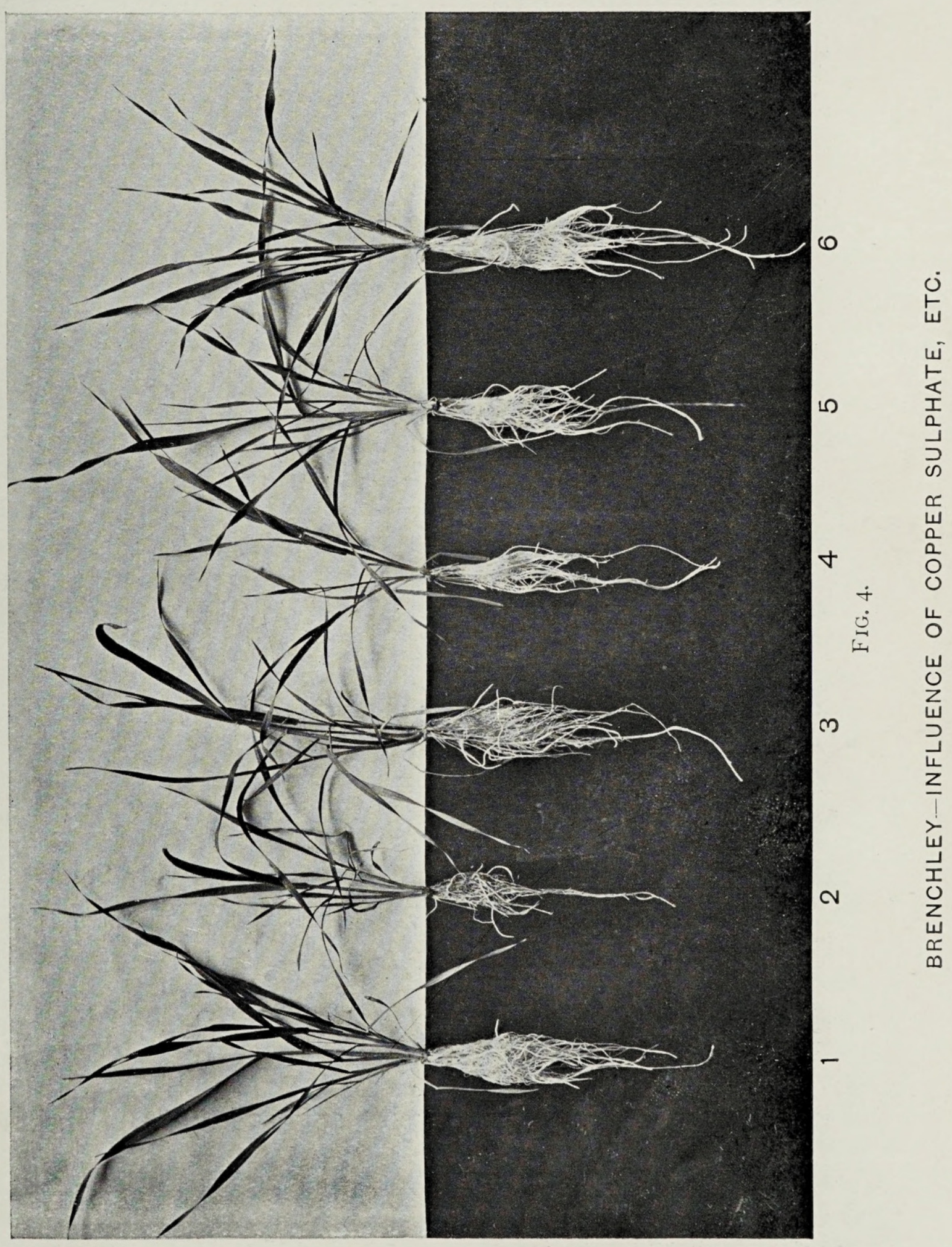




\section{$2 \mathrm{BHL}$ Biodiversity Heritage Library}

Brenchley, Winifred E. 1910. "The influence of copper sulphate and manganese sulphate upon the growth of barley." Annals of botany 24, 571-583. https://doi.org/10.1093/oxfordjournals.aob.a089289.

View This Item Online: https://www.biodiversitylibrary.org/item/262605

DOI: https://doi.org/10.1093/oxfordjournals.aob.a089289

Permalink: https://www.biodiversitylibrary.org/partpdf/319797

\section{Holding Institution}

New York Botanical Garden, LuEsther T. Mertz Library

\section{Sponsored by}

BHL-SIL-FEDLINK

\section{Copyright \& Reuse}

Copyright Status: Public domain. The BHL considers that this work is no longer under copyright protection.

This document was created from content at the Biodiversity Heritage Library, the world's largest open access digital library for biodiversity literature and archives. Visit BHL at https://www.biodiversitylibrary.org. 